\title{
CONCRETE LUNAR BASE INVESTIGATION
}

\section{N $93-17445$}

\author{
T. D. Lin
}

Construction Technology Laboratorles, Inc. 5420 Old Oncbard Road

Skokde IL 60077

Jonathan A. Senseny, Larry D. Arp, and Charles Lindbergh

Tbe Department of Civd Engineering

The Citadel

Cbardeston SC 29409

\begin{abstract}
This paper presents results of structural analyses and a preliminary design of a precast, prestressed concrete lunar base subjected to I-atm internal pressure. The proposed infrastructure measures 120 ft in diameter and $72 \mathrm{ft}$ in beight, providing 33,000 sqft of work anea for scientific and industrial operations. Three loading conditions were considered in the design: (1) during construction, (2) under pressurization, and (3) during an air-leak scenario. A floating foundation, capable of rigid body mtation and translation as the lunar soll beneath it yields, was developed to support the infrastricture and to ensure the airtightness of the system. Results reteal that it is feasible to use precast, prestressed concrete for construction of large lunar bases on the Moon.
\end{abstract}

\section{INTRODUCTION}

Scientific and industrial operations on the Moon require suitably shielded structures. Small structures for limited scientific activities may be constructed from structural elements prefabricated on Earth and transported to the Moon. However, large industrial structures on the Moon must be constructed using in situ lunar materials. A potential material for such construction would be concrete.

Feasibility studies on lunar cement production (Lin, 1987) and experimental studies on lunar concrete ( in et al., 1987) provide scientific evidence that quality concrete can be produced from lunar materials. Concrete, a thermally and chemically stable construction material, can withstand the harsh lunar environment.

One of the innovatively designed elements that contributes to the feasibility of constructing a large concrete lunar base is curved panels. A curved panel, with its concave side facing outward and supported by columns along its straight edges, will develop compressive stresses when subjected to internal air pressure. Concrete performs very well under compressive force. This design will make better use of concrete than a hoop prestressed concrete tank does. Other innovative concepts such as tension-compression columns and a floating foundation contribute greatly to the successful design of the proposed concrete lunar base. Engineering data on lunar concrete needed in structural analyses were taken from test results obtained in Lin et al. (1987).

\section{OBJECTIVES}

The objectives of the study are to perform structural analyses and to evaluate the economic and technological feasibility of a preliminary design for lunar concrete structures.

\section{STRUCTURE}

Figure 1 shows the proposed three-story concrete structure with a 24 -ft story height and a 120-ft diameter. The reason for choosing this particular height is to provide work space suitable for industrial operations and flexibility of converting it into two 12-ft stories if more living quarters are needed. The core structure located at the center of the system is a self-contained cylindrical unit with an inside diameter of $20 \mathrm{ft}$. This unit provides astronauts with safety shelters in case air leaks occur in the base.

Figure 2 shows major structural elements of the proposed lunar base. These elements, based on structural performance, can be classified into four types: compression, flexural, tension-flexural, and tension-compression. According to types, the structural elements include curved panels, floor/ceiling slabs, roof/ground floor slabs and exterior columns, core cylinder, and tensioncompression columns respectively.

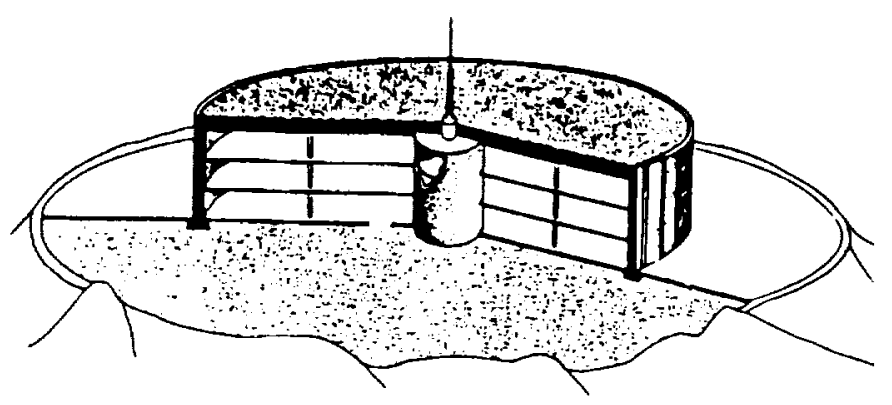

Fig. 1. Proposed three-level concretc lunar base. 


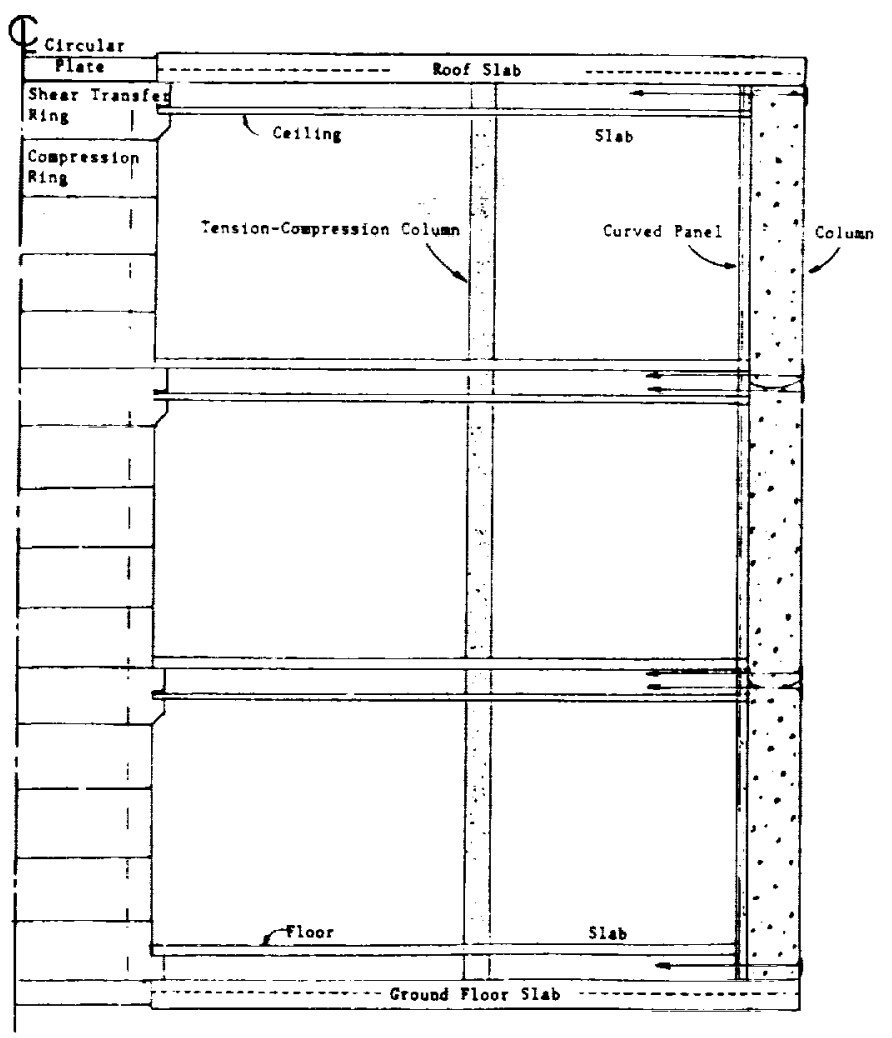

Fig. 2. Major structural elements.

The determination of element sizes considers the workable space in the future concrete plant and the lifting capacity of future lunar robots (assumed $20,000 \mathrm{lb}$ ). The space shuttle's external fuel tank measures $27 \mathrm{ft}$ in diameter and $154 \mathrm{ft}$ in length. Two fuel tanks will make an ideal concrete plant. With a presumption of an external tank utilization, a maximum width of $24 \mathrm{ft}$ for the proposed structural elements is recommended.

\section{LOADS}

Because there is no atmosphere on the Moon, wind loads can be neglected in the design. Although thousands of moonquakes occur each year, their energy is generally less than a Richter magnitude of 2. Consequently, the effect of seismic loads of this scale is considered insignificant. However, the largest moonquake recorded is approximately a magnitude of 4 (Williams and Jadurck, 1980). The occurrence frequency and locations are not reported. All design loads, except internal air pressure, were multiplied by a factor of $y_{0}$ to account for the weak lunar gravity.

For industrial operations, a live load of $600 \mathrm{psf}$ ( $100 \mathrm{psf}$ on the Moon), the heaviest live load recommended by the Uniform Building Codes (The National Building Code, 1985), was used. The air volume in the proposed lunar base, weighing $10 \mathrm{kips}$ on the Moon, was also included in design computations.

The dead loads include a suggested $18 \mathrm{ft}$ of lunar soil ( $300 \mathrm{psf}$ ) on the roof for radiation shieldings, and $25 \mathrm{lb} / \mathrm{cu} \mathrm{ft}$ of concrete.

Load factors of 1.7 for live loads and 1.4 for dead loads recommended by ACI 318 building codes (Building Code Requirements for Reinforced Concrete, 1983) were applied in the design to increase the safety factor. To be conservative, the internal air pressure was treated as live load.
One of the major concerns in designing lunar structures would be the internal air pressure due to the vacuum condition on the Moon. One-atmosphere pressure, equivalent to a 2100 -lb force acting on a square foot area, exceeds by 20 times the live load required by the Uniform Building Codes for an auditorium structure on Earth. Subsequently, a factored air pressure of 3600 psf was used in structural analyses.

The proposed lunar base is of a precast, prestressed concrete structure. Prestressing will be applied to the structural elements by means of a post-tensioning procedure.

Three loading conditions were analyzed to ensure structural safety. The conditions and their design loads are (1) during construction: factored dead loads only; (2) in service: factored dead and live loads, air pressure, and prestressing; and (3) in the event of air leaks: factored dead and live loads and prestressing.

\section{CONCRETE DATA AND DESIGN GUIDES}

Concrete data needed in the design computations were taken from test results obtained by lin et al. (1987). They include the compressive strength of $10,970 \mathrm{psi}$, flexural strength of $1206 \mathrm{psi}$, modulus of elasticity of $3.1 \times 10^{6} \mathrm{psi}$, and thermal expansion coefficient of $2.9 \times 10^{-6} \mathrm{in} / \mathrm{in} / \mathrm{F}$.

Lunar ilmenite is a candidate material for manufacturing steel. However, no data on lunar reinforcing steel and strands are presently available. For convenience, the existing steel data commonly used in design were assumed in the computations.

The design procedures basically followed the ACI 318-83 building codes (Building Code Requirements for Reinforced Concrete, 1983) for reinforced and prestressed concrete elements. The PCI Design Handbook was used as a guide in determining prestressing and selection of tendons.

\section{ANALYSES AND PRELIMINARY DESIGN}

Connections between precast concrete members are often the most important factor influencing the structural analysis of the proposed lunar structure. Careful considerations for connections were exercised to avoid stress concentrations and air leaks. Suitable elastomeric pads have been considered to cushion members at joints. An epoxy coating or sealant that hardens without oxidation can be applied on the interior surfaces of concrete elements to prevent air permeation. The use of elastomeric pads and sealants requires an in-depth study and is beyond the content of this program.

The use of pads at joints will undoubtedly allow connected elements to rotate. A member that rotates at supports may be treated as a statically determined structure. The computations for moments and shears for a simply supported member yield conservative results.

Most structural elements for the proposed infrastructure are prestressed concrete members. For a prestressed member, the moments induced by the post-tensioning are directly proportional to the eccentricity of the centroid of tendons with respect to the neutral axis of the members. When members are joined together by post-tensioned tendons, some degree of joint rigidity will develop. The moments on members in the vicinity of the joint due to post-tensioning may no longer be directly proportional to the tendon eccentricity (Post-Tensioning Manual, 1982). Moments that are induced by the primary moments are called secondary moments. A secondary moment may affect the computational procedures for deflections. This study does not take into account the secondary moments and deflections. 
The design of prestressed concrete members was carried out based on the concept that if there are no tensile stresses in the concrete, there can be no cracks. To achieve zero tensile stresses in concrete members, high-strength steel can be used to carry tension while concrete carries compression to form a resisting couple against the bending moments. A familiar equation (Lin, 1967) that satisfies these assumptions is presented as the following

$$
\mathrm{f}=\frac{\mathrm{F}}{\mathrm{A}} \pm \frac{\text { Fey }}{\mathrm{I}} \pm \frac{\mathrm{My}}{\mathrm{I}}
$$

where $\mathrm{f}=$ stress, $\mathrm{F}=$ prestress force, $\mathrm{e}=$ eccentricity between cgs of prestress and neutral axis, $M=$ moment due to loads, $y=$ distance from neutral axis to the point where stresses are to be calculated, and I = moment inertia of the cross section.

The load balancing method ( $\operatorname{Lin}, 1967$ ) was also used in determining prestresses to balance the applied loads. The balancing load, $v$, produced by a parabolic tendon can be expressed

$$
v=\frac{8 \mathrm{Fh}}{\mathrm{L}^{2}}
$$

where $h$ is the sag of tendon profile and $L$ is the span length.

Designing prestress to counteract loads or bending moments for structures on Earth is straightforward. However, designing lunar structures that may experience air leaks in which the air pressure diminishes and the prestress in concrete remains could be complicated. The retained prestress may violently break the members if concrete is not properly reinforced. The following briefly describe the designs of structural elements (details of designed elements are included in Lin et al., 1988).

\section{Panels}

Figure 3 shows a plan view of a reinforced concrete panel simply supported by columns at both ends. A curved panel subjected to a factored atmospheric pressure $(3600 \mathrm{psf})$ on its

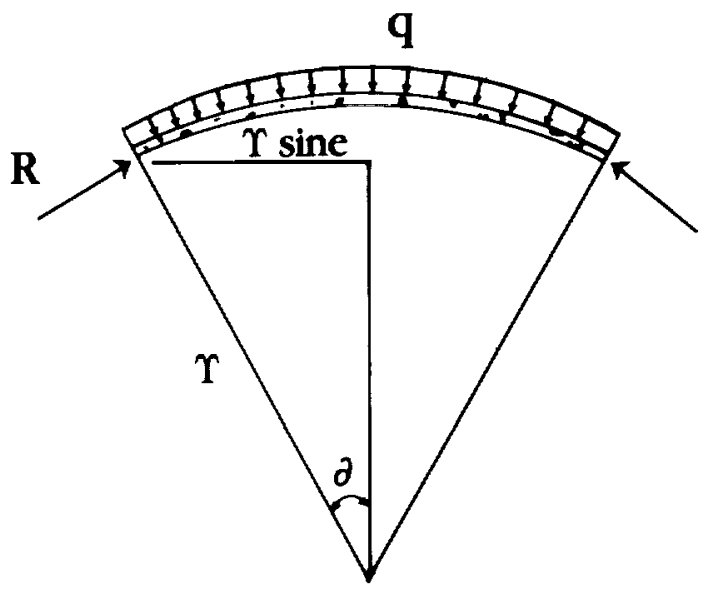

outer surface will develop compressive stresses. The reaction at supports can be expressed as $R=3600 \Upsilon$, where $\Upsilon$ is the radius of the panel. With this equation and section 14.5 .2 of $\mathrm{ACI} 318-$ 83, a 6-in-thick panel with a 20 -ft radius was selected. The minimum reinforcement provision (section 7.12 of ACI 318) yieids the required reinforcing steel.

\section{Roof Slabs}

The roof system of the proposed infrastructure consists of 33 identical fan-shaped slabs. Each slab is composed of three $12 \times$ 16-in radial joists and a 10-in-thick deck with variable widths.

Dead loads include the 18-ft-thick lunar soil and concrete weights, while live loads include envisioned solar energy collectors on the roof and the 1-atm internal air pressure applied to the bottom surface of the slab. Figure 4 provides the loading information. The linear variation of loads is attributed to the
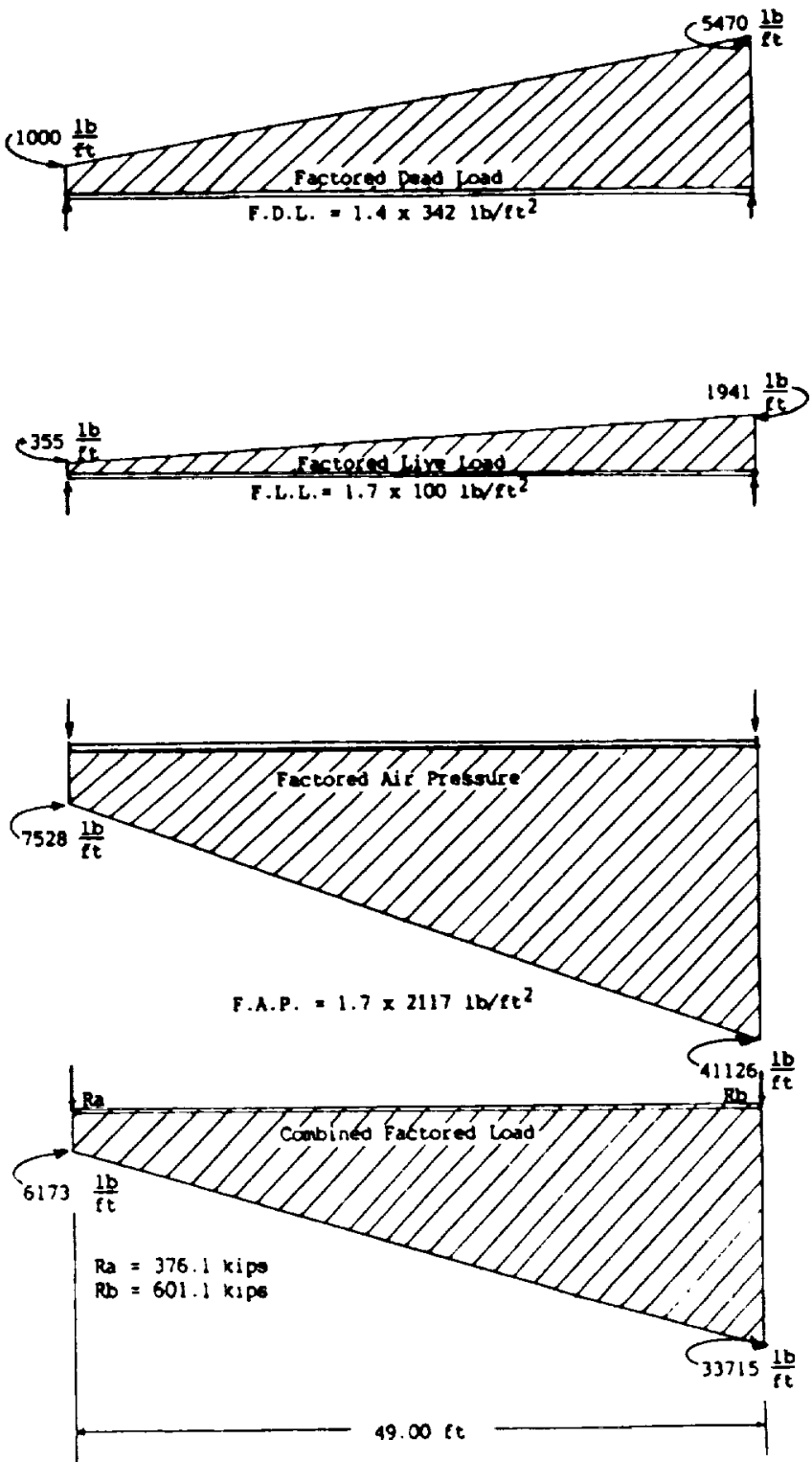

Fig. 4. Loads on roof slabs

Fig. 3. A plan view of a curved panel. 
variable width of the slab. Because the air pressure is much greater than the sum of dead and live loads, the bending moments due to the combined loads are dominated by air pressure and are too big for a practically sized slab to resist. To resolve this problem, possibilities of using in-span restraints to confine upward deflections of the slab were investigated in hopes of reducing the bending moments. It was found that a downward force of $407 \mathrm{kips}$ at the maximum bending moment location, $27.2 \mathrm{ft}$ from the interior support, will decrease the maximum bending by $63 \%$. The 407-kip force will be supplied by the so-called tensioncompression column, which will be discussed in a later section. Figure 5 shows the computed moment diagrams of the slab without and with a tension-compression column (see the parabolic curve and triangular curve respectively).

It is tedious to determine the critical section of a roof slab with variable widths subjected to discontinuous nonlinear moments. To simplify the computations, ratios of the bending moment to the moment inertia at selected sections were computed. By comparing the calculated ratios, the section at $16 \mathrm{ft}$ from the interior support was found to be the most critical and was used in the design. The designed roof slab is shown in Fig. 6.

\section{Ground-Floor Slabs}

The behavior of the ground-floor slabs during service is similar to that of the roof slabs. However, the bending moments developed in the ground-floor slabs are greater than those of roof slabs. The increase in bending moments results from there being no 18 -ft-thick lunar soil placed on the ground-floor slab to counteract the air pressure, and the live and dead loads act in the same direction as the air pressure. Accordingly, deeper joists and more prestressing strands were required for the ground-floor slabs. Figure 7 shows a designed ground-floor slab.

\section{Ceiling Slabs and Floor Slabs}

like the roof system, the ceiling and floor systems each consist of 33 one-way slabs. However, their loading conditions are quite different. Because they are completely enclosed by the infrastructure, the air pressurization in the lunar base has no sffect on them. The equilibrium condition of air pressure on these slabs accounts for much smaller loads and simplifies the design procedures.
Nevertheless, ceiling slabs were designed to carry horizontal steel tendons ( $25 \mathrm{psf}$ ) during construction, while floor slabs were designed to carry heavy industrial equipment ( $100 \mathrm{ps})$. With these assumed live and dead loads, the maximum bending moments and shears for both types of slabs were calculated.

The strength design method recommended by ACI building codes was followed to calculate nominal moment and shear strengths, and to determine the principal reinforcement and stinup details.

\section{Tension-Compression Columns}

In the case of air leaks, the air pressure in the structure diminishes, but the 407-kip concentric prestressing force remains on the roof and ground floor slabs. This force is sufficient to cause either slab to collapse if no other schemes were designed to counteract the force. To solve this engineering problem, a concrete column with unbonded tendons was designed to restrict slab deflections. This design enables the column to perform dual functions. The column acts as a tension member in a pressurized condition and as a compression member in the event of air leaks. Since there are no documented references on such columns available in concrete structural textbooks, they are referred to as "tension-compression columns."

As discussed, the tension-compression columns were designed to decrease the bending moments and to minimize the thicknesses of the roof and ground floor slabs. Conceivably, the use of tension-compression members offers economic benefits to the proposed lunar base construction.

If a tension-compression column were used for each roof slab, the spacing between successive columns would be about $5.5 \mathrm{ft}$, which is too small for industrial operations. For this reason, curved beams about $22 \mathrm{ft}$ in length, extending across three slabs, will be installed along the circular path at a distance of $27.2 \mathrm{ft}$ from the outer face of the core structure, on the roof slabs and under the ground floor slabs, to provide a force transfer mechanism to the tension-compression columns. This design will increase the spacing between columns to about $25 \mathrm{ft}$.

The design of the proposed tension-compression columns to resist tension is straightforward. The required tensile force of 1220 kips $(=407 \times 3)$ in each column determines the needed number of strands ( 30 strands of 0.6-in diameter). In an air-leak scenario, the restraining force immediately transfers to the

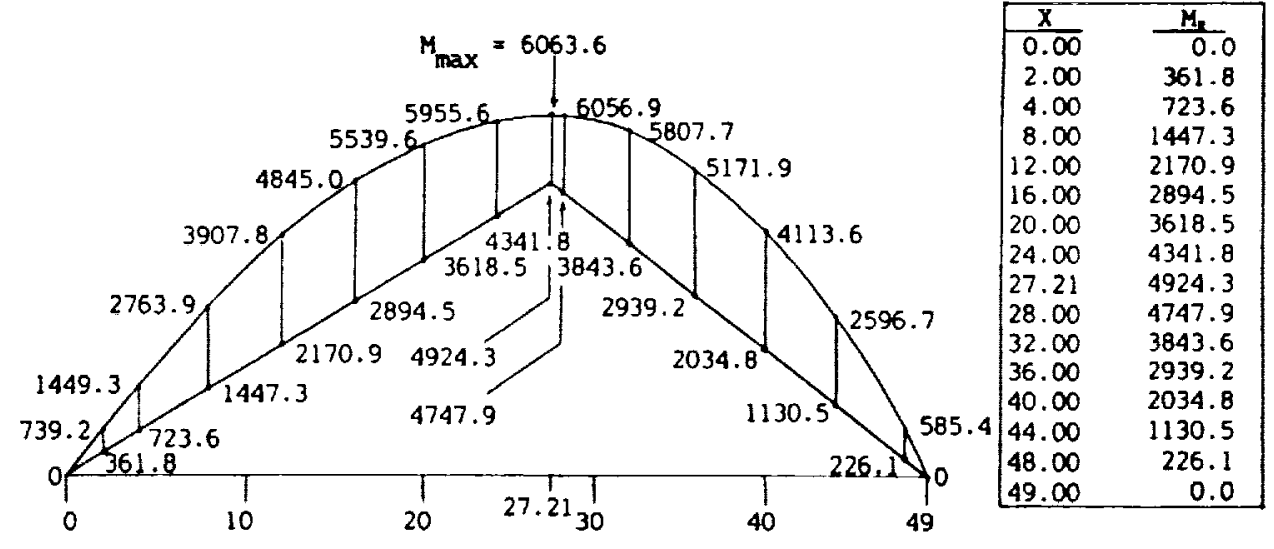

\begin{tabular}{|c|}
\hline Difference $\left(M_{1}-M_{.}\right)$ \\
0.0 \\
377.4 \\
725.7 \\
1316.6 \\
1736.9 \\
1950.5 \\
1921.1 \\
1613.8 \\
1139.3 \\
1309.0 \\
1964.1 \\
2232.7 \\
2078.8 \\
1466.2 \\
359.3 \\
0.0 \\
\hline
\end{tabular}

Fig. 5. Moment diagrams

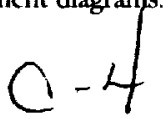




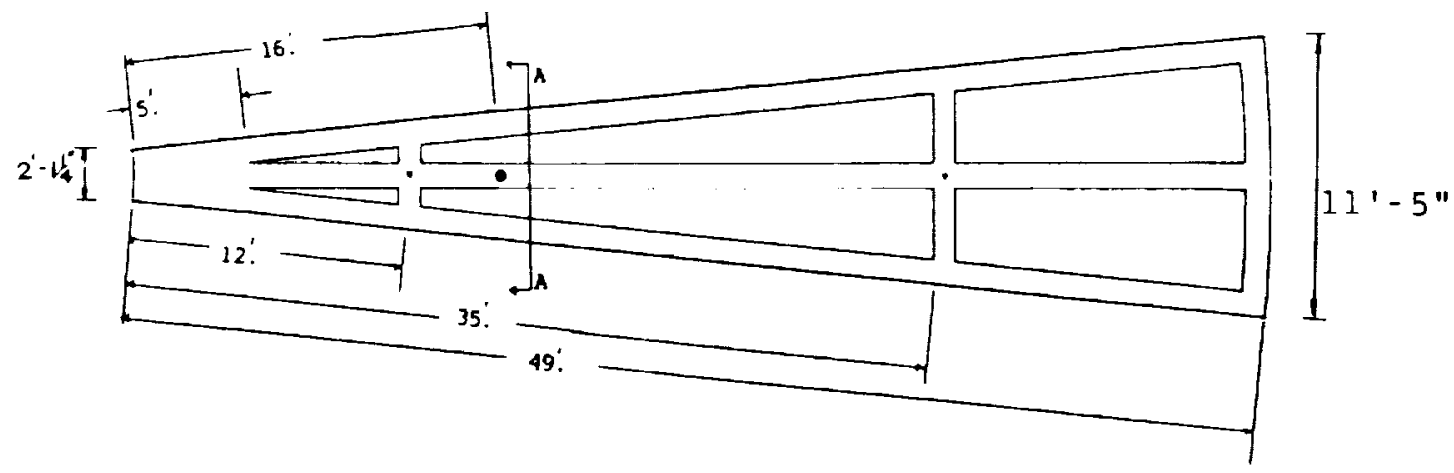

- Most critical section

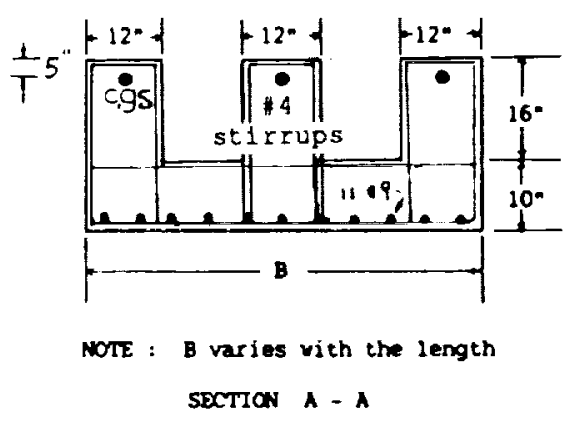

Fig. 6. A designed roof slab.

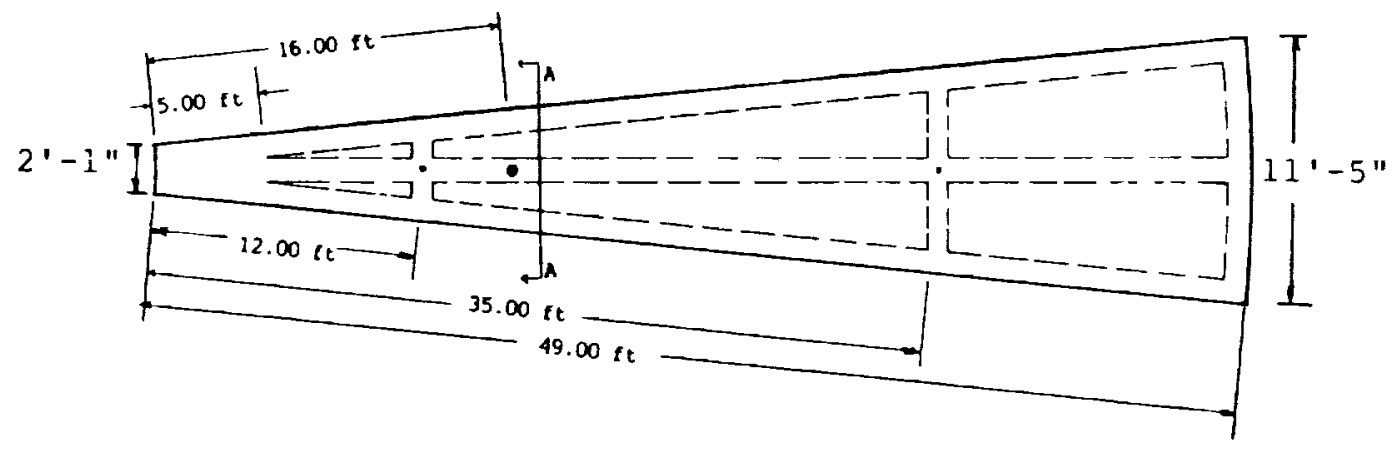

- Most Critical section

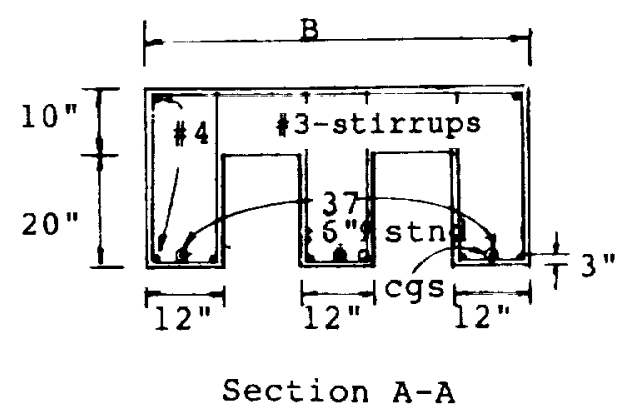

Fig. 7. A typical ground-floor slab. 
column. The column must be capable of resisting the sum of the 1220-kip force and the projected live and dead loads that it may have to support. A 24-in circular column was selected from tables on pages 4-40 of the CRSI Handbook (1984). The designed tension-compression column is shown in Fig. 8.

\section{Exterior Columns}

There are 33 exterior columns on each floor of the three-story structure to laterally support the curved panels. In the vertical direction, three columns are aligned to form a 72 -ft support for the roof slab and ground floor slab. These three columns are secured in position by prestressing vertical tendons that run through the columns and horizontal tendons that run in between the floor and ceiling slabs (see Fig. 9).

Columns for an ordinary structure on Earth act as compression members. For a pressurized structure on the Moon, the columns behave like a tension member or a beam. The design of the exterior columns followed the beam design procedures.

How columns are tied together in a multistory structure influences the serviceability of the lunar base. A connection mechanism, in which the lower end of an upper column in a semispheric shape sits on the dish surface of the top end of the lower column to form a roller-bearing joint, allows the jointed columns to rotate against each other and nullifies the bending moments at joints.

The prestressing tendons designed to balance air pressure in each column extend about $1 \mathrm{ft}$ beyond the joint and are anchored to the adjacent columns. This arrangement will add safety to the column connections either in normal service or in an air-leak condition. The exterior columns are reinforced with rebars to prevent concrete from cracking due to stress reversals in an airleak scenario. Section A-A of Fig. 9 gives details on reinforcing bars.

\section{Core Structure}

The inner core structure is a self-contained unit capable of withstanding $1 \mathrm{-atm}$ pressure. Structurally speaking, the core structure serves as an interior support to slabs so as to reduce

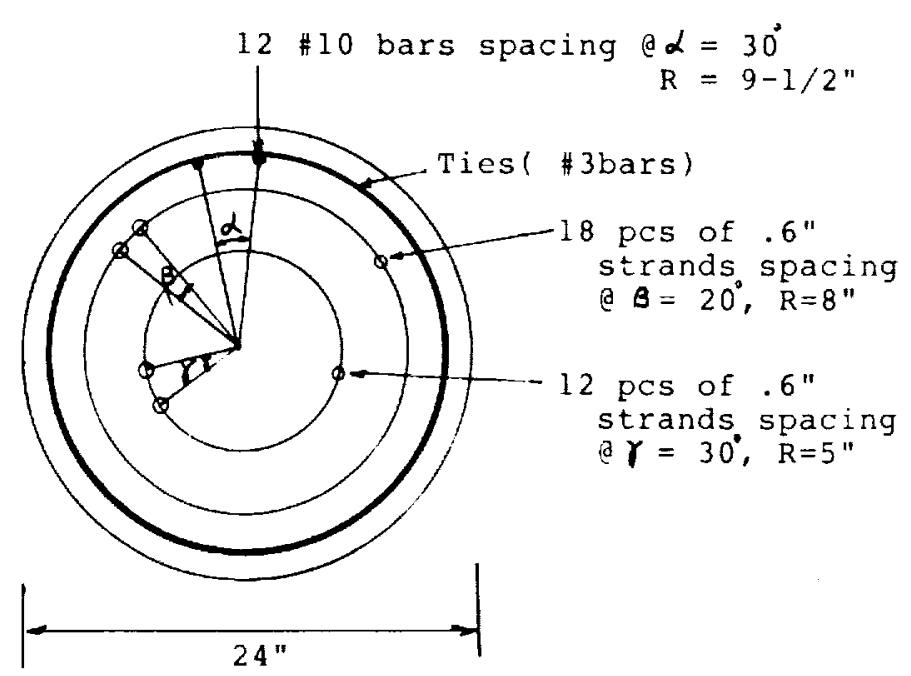

Fig. 8. Cross section of a tension-compression column. slab span. The core structure will be fabricated using ring and plate elements with a weight limit of $10 \mathrm{t}$.

Based on the structural function, two types of rings were designed: the shear transfer rings and the compression rings. The shear transfer rings are elements that have corbels to support the slabs. All rings have a 20 - $\mathrm{ft}$ inside diameter and thicknesses of $2 \mathrm{ft}$ and $1 \mathrm{ft}$ for shear transfer and compression rings respectively. All rings except the shear transfer ring at the top are $4 \mathrm{ft}$ in height. Again, elastomeric pads will be used to ensure airtightness at all joints when the core structure is prestressed.

Both pressurized and depressurized conditions were considered in the design. Under the pressurized condition the circumferential stresses in the wall become the dominant design factor. The hoop force per foot of the ring subjected to $3600 \mathrm{psf}$ internal air pressure is $36 \mathrm{kips}$. To balance this hoop force only one 0.6 -indiameter seven-wire strand is needed. Figure 10 shows the suggested hoop tendons. A complete circular tendon will be made from three segmental tendons, each having a subtended angle of $120^{\circ}$. Tendons that overlap in brackets ensure the continuity of hoop forces.

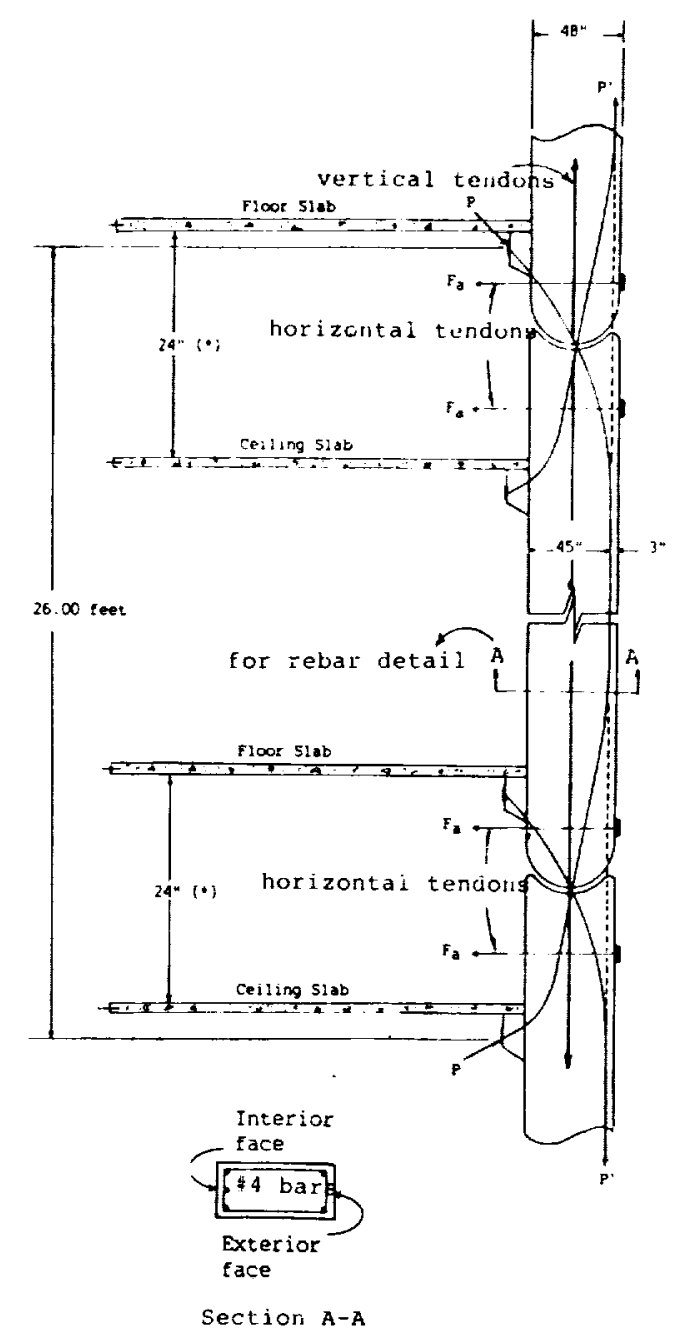

Fig. 9. Exterior columns and connections. Note: $(\cdot) \cdot 24$ " space between the floor and ceiling slabs is to provide room for horizontal tendons. 


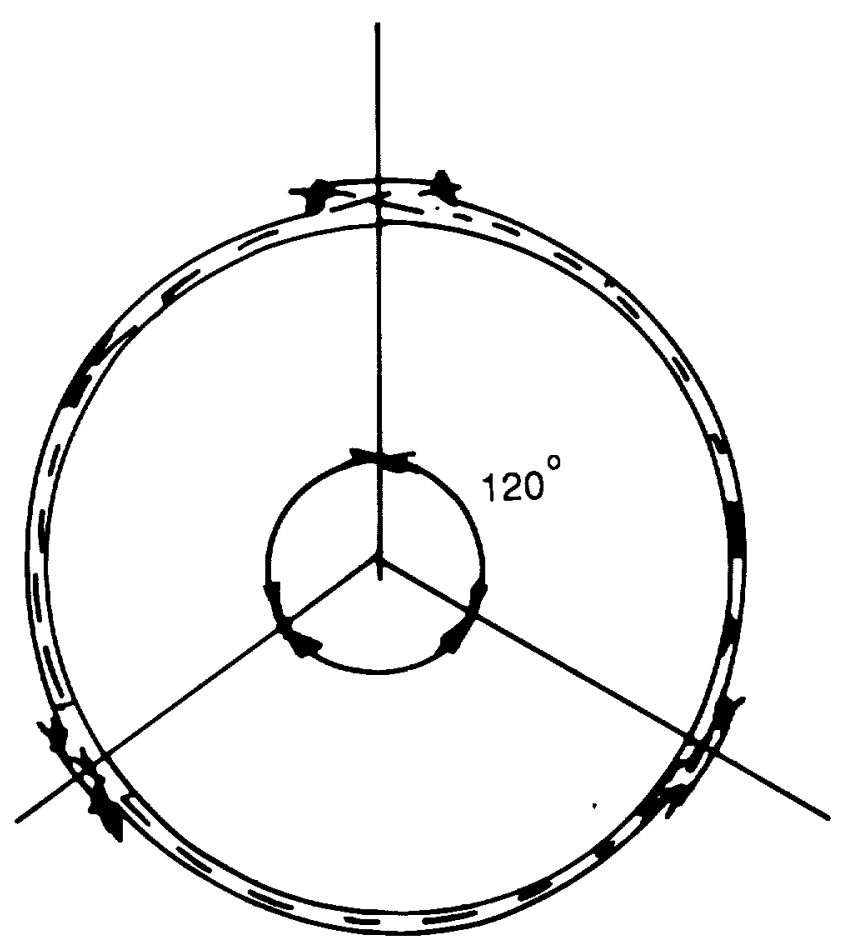

Fig. 10. Hoop tendons.

The vertical strands in the rings that hold the core elements together were determined from factored loads including air pressure, live loads, and dead loads acting on the cover plates. The calculated results show that 38 strands of 0.6 -in diameter are needed to hold the cover plates and rings in position to contain the anticipated 1-atm air pressure.

Circular cover plates were designed as a two-way slab simply supported along its perimeter. The plate theory (Timoshenko and Woinowsky-Krieger, 1959) was used in calculating the maximum bending moment at the plate center. The two-dimensional balancing method was used to determine the needed strands. It was found that a 12 -in-thick circular concrete plate with six 0.6 in-diameter strands for every 11.5-in strip will satisfy the design. The circular plates will be reinforced with conventional rebars to resist bending moments during construction.

\section{ESTIMATE OF MATERIAIS}

In brief, the designed infrastructure weighs approximately $8500 t$ on Earth ( $1400 \mathrm{t}$ on the Moon), of which concrete is about $8000 \mathrm{t}$, strands $110 \mathrm{t}$, and reinforcing bars $250 \mathrm{t}$. To make $8000 \mathrm{t}$ of concrete needs approximately $1000 \mathrm{t}$ of cement and $330 \mathrm{t}$ of water, assuming free moisture in concrete will be captured for reuse. All these materials except hydrogen can be obtained from the Moon. The amount of hydrogen to be transported from Earth is $36 \mathrm{t}$.

\section{FLOATING FOUNDATION}

As reported, the depth of the lunar regolith varies from $0.5 \mathrm{~m}$ to $40 \mathrm{~m}$ in the mare and highland regions of the Moon. Laboratory studies (Williams and Jadwick, 1980) on returned samples show an average bulk density of about $1.66 \mathrm{~g} / \mathrm{cm}^{3}$, porosity of around $45 \%$, cohesion strength of 0.1 to $1.0 \mathrm{KN} / \mathrm{m}^{2}$, and absolute dryness.
Based on astronaut's footprints, applying a pressure of $10 \mathrm{KN} / \mathrm{m}^{2}$ would normally settle the soil approximately $1 \mathrm{~cm}$. These mechanical properties of the soil make conventional compaction, piling, and mat footing impractical for construction on the Moon.

One of the important requirements for the lunar base construction is to provide airtightness and structural integrity. Therefore, the tolerance for differential settlements of the foundation must be extremely small. To achieve this objective, an innovative concept of a floating foundation for lunar construction was developed to minimize possible relative movements between structural members of the superstructure due to foundation settlements. The proposed foundation structure will be made with precast concrete members. A rigidly assembled substructure that could have rigid body rotations and translations as the lunar soil beneath it yields can support the superstructure like a ship carrying stacks of cargo on the high sea. This design could practically eliminate differential movements among elements of the superstructure.

A truss structure made with precast concrete members is not common. The main reason is that when a truss is subjected to loads, some of its members may develop tensile stresses that could cause cracks and damage to concrete. However, if one can develop a truss, subjected to loads at the top and soil reactions at the bottom, to produce compressive stresses throughout its members, the feasibility of using concrete for truss construction can be realized. Through many trial analyses, one such truss was found and is shown in Fig. 11.

The dish-shaped foundation will be fabricated from four or six trusses. The assemblage of trusses and methods for connection require careful studies. The design of the proposed foundation is left for future study.

\section{CONCLUSION}

Precast, prestressed concrete has many material and structural merits for the proposed lunar base construction. The attractiveness of concrete structures lies in the fact that most materials except hydrogen for making concrete, steel, and water are available on the Moon. To build the proposed infrastructure $120 \mathrm{ft}$ in diameter and $72 \mathrm{ft}$ in height requires about $8000 \mathrm{t}$ of concrete, $110 \mathrm{t}$ of prestressing steel, and $250 \mathrm{t}$ of rebars. To make the $8000 \mathrm{t}$ of concrete requires about $36 \mathrm{t}$ of hydrogen. Hydrogen, the lightest element known to man, is the only material that needs to be transported from Earth.

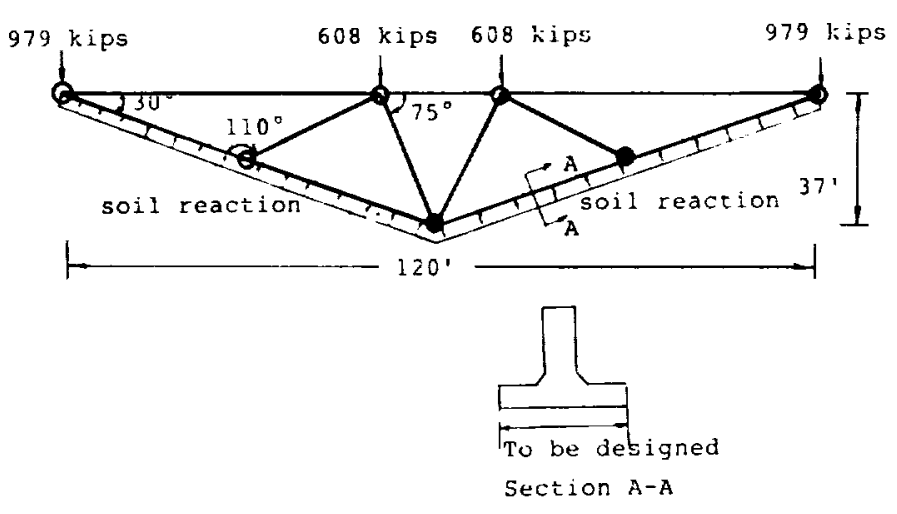

Fig. 11. A proposed floating foundation 
The designed prestressed concrete structure provides $33,000 \mathrm{sq} f$ of work area, large enough for industrial productions including the assemblage of rockets in a horizontal position. The designed infrastructure is capable of supporting a dish-shaped solar energy collector with a diameter of $120 \mathrm{ft}$ on its rooftop. Photovoltaic solar panels as high as the lunar base structure can be erected along the perimeter of the base. These solar energy installations serve as radiation shields as well as energy supply sources.

It is concluded that to build concrete structures to safely contain 1-atm air pressure on the Moon is technically feasible. This investigation is only a preliminary design; more research and design studies are needed to complete a final design.

Acknowledgments. This research project was funded by the solar System Exploration Division of the National Aeronautics and Space Administration (NASA), Johnson Space Center, Houston, Texas and the Prestressed Concrete Institute (PCI) and Technology Commercialization Center, University of Chicago. Contract support was provided by Lockheed EMSCO.

\section{REFERENCES}

Building Code Requirements for Reinforced Concrete (1983) ACI Standard 318-83, Detroit, Michigan. $155 \mathrm{pp}$

CRSI Handbook (1984) Sixth edition. Concrete Reinforcing Steel Institute, Schaumberg, Illinois. $1024 \mathrm{pp}$.

Lin T. D. (1967) Design of Prestressed Concrete Structures, 2nd edition. Wiley, New York

Lin T. D. (1987) Concrete for lunar base construction. Concr. Int., 9.

Lin T. D., Love H., and Stark D. C. (1987) Physical properties of concrete made with Apollo 16 lunar soil. Broc. ALAA Conf. American Institute of Aeronautics and Astronautics, New York.

Lin T. D., Senseney J. A., Arp L. D., and Lindhergh C. (1988) Concrete lunar base investigation. J. Aemosp. Eng., 3 .

The National Building Code (1985) Engineering and Safety Service, New York.

Post-Tensioning Manual (1981) Third edition. Post-Tensioning Institute, Phoenix. 323 pp.

Timoshenko S. P. and Woinowsky-Krieger S. (1959) Theory of Plates and Shells, 2nd edition. McGraw-Hill, New York

Williams R. J. and Jadwick J. J. (1980) Handbook of Lunar Materials. NASA RP- 1057. 